\title{
A Systems-Thinking View on Climate Change
}

\author{
Peter Blokland* \\ Delft University of Technology, The Netherlands
}

Submission: November 27, 2019; Published: December 16, 2019

*Corresponding author: Peter Blokland, TUDelft - TBM - S3G - Jaffalaan 5 - 2628 BX Delft - The Netherlands \& Hugo Verrieststraat 13 - 2540 Hove - Belgium

\begin{abstract}
Many perceptions exist regarding climate change. These perceptions determine the action that is given to this global challenge. To come to the right decisions and action, it is important that the quality of those perceptions is as high as possible, because wrong or inadequate decisions and action could have grave consequences for the people on planet Earth. A systems-thinking perspective can help in gaining the required quality of perception to effectively and efficiently address this global challenge.
\end{abstract}

Keywords: Climate change; Global challenge; Systems-thinking; Spectrum; Earth's atmosphere

\section{Introduction}

When discussing climate change, different perceptions and realities come to the table. Although only one reality exists, perceptions range from complete climate change denial to sheer panic about what is perceived to be happening. Unfortunately, one could ask whether both sides of this spectrum get to the right conclusions or not, as their systemic perspective on what is happening could be lacking. One thing is certain, temperature in Earth's atmosphere is rising and most likely the human race plays a significant role in this change. Also, certain, Earth's climate has changed in the past as well even without human interference. So, does the climate care? Do we have to "save" the climate? Or, do we humans care and do we have to save humans? I don't think the climate cares, I also think that climate will change over time, as it has in the past. But I'm certain that people care, and that action is required to save humans, whether climate changes as a result of human interference or not.

\section{A systems thinking perspective}

In systems thinking, one of the laws of systems thinking indicates that today's problems are the result of yesterday's solutions. Although climate change has occurred in the past without any relationship to mankind, today's climate issues are undeniably related to human interactions and today it is clear this poses a problem in all parts of the world. These human interactions inducing climate change are in fact the solutions that mankind developed for other problems in the past. In fact, its the solutions created by mankind, to aim for a better life that are at the core of the current issues. Advances in science in past centuries have generated a huge progress in medicine, healthcare and safety and it is also responsible for increased performance in food production, reducing famine and its associated catastrophes in the world. Ultimately, it also allowed to create successful industries, producing solutions that make our lives easy and comfortable.

As a result of all of these great achievements, the world population has exploded. People don't die from trivial diseases or famine anymore. Child mortality rates have diminished enormously and our abilities to prolong life improve every day. Today people survive and grow old, where in the past they would die. Improved healthcare, attention to safety and increased comfort, result in a longer life, adding more to the amount of people already on the planet. Who all need food, comfort and energy to survive and thrive, and this is why greenhouse gas expulsion has increased drastically. Moreover, people looking for living space create their "lebensraum" by burning down the rainforest, as such reducing Earth's capacity to regulate the atmosphere. Likewise, oceans are polluted in a way that its regulating capacity is also compromised.

As a result of progress and innovation, the invention of nuclear weapons and consequently nuclear power, created a boost in both societal safety and individual comfort. For instance, after two worldwide conflicts in the first half of the previous century, the advent of nuclear weapons prevented opposing parties to wage war at a global scale. Ever since, conflicts have less impact on the number of lives of young men lost in conflicts. Then again, nuclear energy allowed societies to develop themselves due to affordable energy and, as a result, it created an energy addicted society, focussed on comfort and ease. 
Ever more regions in the world aim for that same status of safety and comfort and they rightfully do so. However, today, it adds to the cost of ever-increasing greenhouse gas expulsions, as nuclear energy is no longer a selected, accepted or an affordable choice. As a result, energy production is mainly running on fossil fuels, forests are disappearing and Earth's capacity to balance its climate is rapidly diminishing. As such, it is an inconvenient truth that our climate issues of today result from our efforts to progress and our determination to solve problems and create more value for people and society.

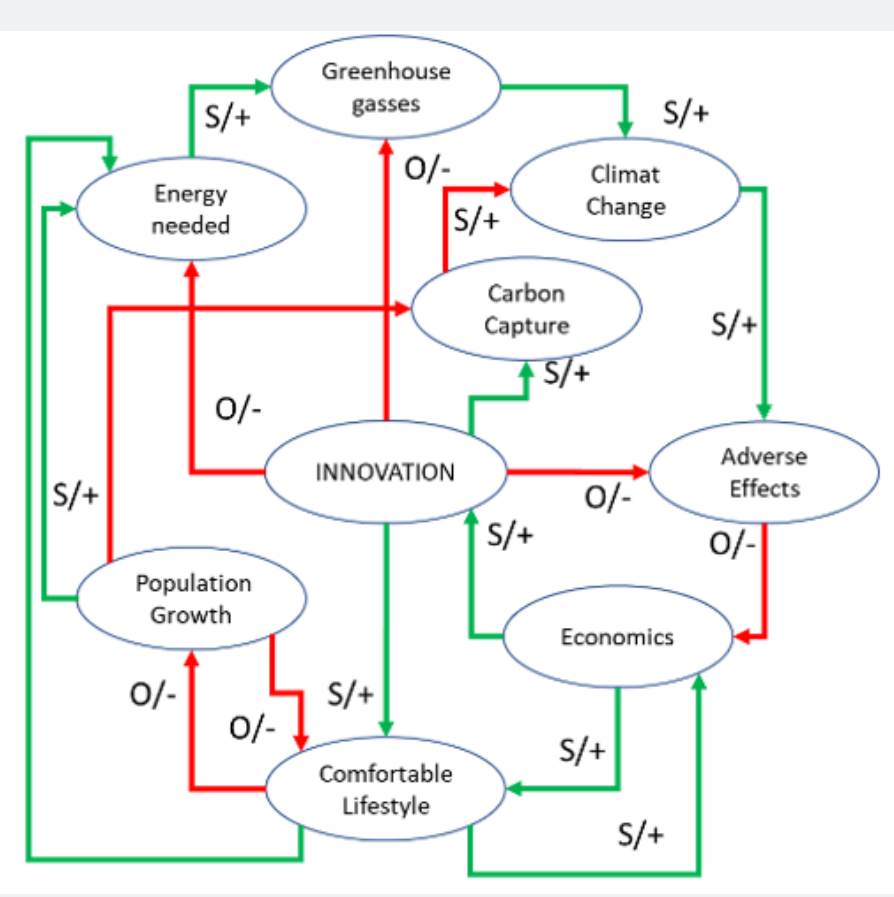

Figure 1: System of Climate Change..

\section{System dynamics}

So, do we need to abandon our efforts to make life easy and comfortable? Do we have to step back to the future, doing less with less? It is time to act, there's no doubt about that.

But before acting, a thorough understanding of the whole system is to be considered. Solutions need to take into account their possible adverse effects when they only concern or address the symptoms instead of dealing with the root causes of the current problem. But what is/are the root cause(s). Is it our abundant lifestyle in developed countries? Is it the population growth in still developing countries? Surely, the answer is more complex than that and many parameters play important roles in this issue. However, sometimes it is beneficial to limit the number of parameters to be able to understand the systems dynamics (Figure 1).

Obvious parameters that certainly play a role in climate change are the expelled greenhouse gasses, energy consumption, our comfortable lifestyle and the adverse effects people are afraid of. Other important parameters are economic power, population growth and the carbon capture by forests and oceans.

In the systemic map in figure 1, the prevailing system is driven by an energy demanding lifestyle and population growth. When, on a local scale, comfort increases, it will require more energy. This leads to a balancing loop in function of the adverse effects of climate change and their impact on the economy of that region. On the other hand, in regions where a comfortable lifestyle is not yet achieved, population growth increases as a result of improved health and safety conditions. To cope with this situation, this results in diminishing carbon capture and creates a reinforcing loop, making things worse, as declining economics hamper progress and the diminishing of populations.

One of the results is immigration, which puts regions with a comfortable lifestyle under pressure, setting another reinforcing loop into motion as economics are then influenced in the same way. Equally, another reinforcing loop can be found in a further population growth as a result of declining lifestyle, adding to the overall loop of increasing adverse effects.

\section{A systemic solution}

Problems can never be solved with the same elements of the system. Something needs to be added to the system to turn it around, doing less with less is not an option. The element to add is innovation, as it allows to influence several parameters at the same time, all creating positive effects in turning around the basic system. However, innovation needs strong economics to grow. It requires investments before results become noticeable. 
In order to turn the system around, having the reinforcing loops going the other way, innovation needs to focus on improving our comfortable lifestyle and spreading this comfort all over the world. This will have a positive effect on economics and population growth. Simultaneously, it needs to address energy consumption to counter the effect of an increased comfortable lifestyle. Furthermore, it must affect the expulsion of greenhouse gasses and carbon capture in a favourable way to reduce the rate of climate change. And, finally, it needs to address the adverse effects of climate change in order to improve economics as an engine of change. The last part is also necessary when climate change occurs when humans are not involved in the root cause.

\section{Mental Models (Conclusion)}

A system, its structure and the dynamics it shows, result from the mental models that generate and support the system. When people think we need to refrain from economic growth and do less with less, the ability to innovate and solve our issues with climate change will decline. However, when mankind succeeds in sharing economic growth and puts a strong focus on innovation, as indicated in Figure 1, it will create reinforcing effects that can produce an outcome to this general concern of climate change. 